\title{
A COMPARATIVE STUDY OF FUNCTIONAL AND RADIOLOGICAL OUTCOME OF PERTROCHANTERIC FRACTURE IN ELDERLY PATIENTS TREATED WITH DYNAMIC HIP SCREW AND PROXIMAL FEMORAL NAIL
}

\author{
Ramesh Balusamy1, Kalyanasundaram Kolundan², Srinivasan Anbu ${ }^{3}$
}

${ }^{1}$ Senior Resident, Department of Orthopaedics, KAP Viswanatham Government Medical College, Tiruchirapalli.

${ }^{2}$ Associate Professor, Department of Orthopaedics, KAP Viswanatham Government Medical College, Tiruchirapalli.

${ }_{3}^{3}$ Associate Professor, Department of Orthopaedics, KAP Viswanatham Government Medical College, Tiruchirapalli.

\section{ABSTRACT}

\section{BACKGROUND}

Pertrochanteric fractures, one of the most common fractures in Orthopaedics are supposed to be the most devastating orthopaedic injuries in elderly. The goal of treatment in Pertrochanteric fracture is early mobilisation of patients to prevent morbidity and mortality. The early mobilisation of post-operative patient depends on the stability of surgical construct. This study was conducted to compare the functional and radiological outcome of Pertrochanteric fractures in elderly patients treated with Dynamic Hip Screw and Proximal Femoral Nail.

\section{MATERIALS AND METHODS}

The present study was carried out in Government Royapettah Hospital/Kilpauk Medical College from 2012 to 2014 . The study consists of a total 40 adult patients of Pertrochanteric factures of femur satisfying the inclusion criteria, who are treated with Proximal Femoral nail (20 cases) and Dynamic Hip Screw (20 cases).

\section{DISCUSSION}

Each case was followed up for at least 6 months and in each visit, clinical radiological and functional outcome was studied. These details were analysed, evaluated and compared. In our study of 40 patients, we had $18(45 \%)$ Intertrochanteric fractures with Evans stable type of fracture pattern and 22 (55\%) cases were of Evans unstable fracture pattern. Out of the 18 Evans stable Intertrochanteric fractures, 12 patients underwent DHS and 6 patients underwent PFN. In the Evans unstable Intertrochanteric fracture group of 22 patients, 8 patients underwent DHS and 14 patients underwent PFN.

\section{RESULTS}

Average time of union in all our 40 patients was about 16 weeks (Range: 12 to 20 weeks).

\section{CONCLUSION}

From our study, we safely conclude that choice of implants depend on the experience of the surgeon and the type of fracture pattern. In our study, we also conclude that fixation of Pertrochanteric fractures aid early rehabilitation and early weight bearing.

\section{KEYWORDS}

Pertrochanteric Fracture, Proximal Femoral Nail, Dynamic Hip Screw, Functional and Radiological Outcome.

HOW TO CITE THIS ARTICLE: Balusamy R, Kolundan K, Anbu S. A comparative study of functional and radiological outcome of pertrochanteric fracture in elderly patients treated with dynamic hip screw and proximal femoral nail. J. Evolution Med. Dent. Sci. 2017;6(5):387-394, DOI: 10.14260/Jemds/2017/87

\section{BACKGROUND}

Pertrochanteric fractures are one of the most common fractures in Orthopaedics. Pertrochanteric fracture is supposed to be the most devastating orthopaedic injury in elderly.1,2,3 There is an increase in the incidence of this fracture now due to road traffic accidents, construction works and rise in elderly population. There exists a bimodal distribution with $10 \%$ of cases in young individuals with history of fall from height and road traffic accidents.1,2 Remaining $90 \%$ of cases are elderly people with history of bone leads the patient to be bedridden for a prolonged period

Financial or Other, Competing Interest: None.

Submission 08-12-2016, Peer Review 04-01-2017,

Acceptance 10-01-2017, Published 16-01-2017.

Corresponding Author:

Dr. Ramesh Balusamy,

\#C 95 SS Residency, 10 $0^{\text {th }}$ A Cross Street,

Thillai Nagar, Tiruchirapalli-620018.

E-mail: rbalusamy505@gmail.com

DOI: $10.14260 /$ jemds $/ 2017 / 87$ and so increased morbidity and mortality occurs. Appropriate treatment of this fracture is a must to prevent these complications. ${ }^{2,3}$ Literature says that about 15 to $20 \%$ of elderly patients with pertrochanteric fractures die within one year of injury if no appropriate treatment is given. ${ }^{4}$

Previously, these fractures were treated conservatively with traction and prolonged bed rest for 10 to 12 weeks followed by ambulation training. Prolonged bed rest leads to increase in morbidity like bed sores, urinary tract infections, respiratory tract infections and joint stiffness. To avoid these complications, operative treatment of these fractures are tried with the aim of early bed to chair mobilisation of these patients. ${ }^{5}$

The goal of treatment in pertrochanteric fracture is early mobilisation of patients to prevent morbidity and mortality and the early mobilisation depends on the stability of surgical construct.6,7

This study was conducted to compare the functional and radiological outcome of Pertrochanteric fractures in elderly 
patients treated with Dynamic Hip Screw and Proximal Femoral Nail.

\section{Aim of the Study}

To compare the functional and radiological outcome of Pertrochanteric fracture in elderly patients treated with dynamic hip screw and those with proximal femoral nail.

\section{MATERIALS AND METHODS}

The present study was carried out in Government Royapettah Hospital/Kilpauk Medical College from 2012 to 2014. The study consists of total 40 adult patients of Pertrochanteric factures of femur satisfying the inclusion criteria, who are treated with Proximal Femoral nail (20 cases) and Dynamic Hip Screw (20 cases). It was a comparative study.

\section{Inclusion Criteria}

1. All patients over 55 years of age with Pertrochanteric fractures.

2. Both stable and unstable Pertrochanteric fractures as classified by Evan. ${ }^{8}$

3. Intertrochanteric fractures and Intertrochanteric with Subtrochanteric extension.

\section{Exclusion Criteria}

1. Patients with pure subtrochanteric fractures.

2. Patients with pathological fracture.

3. Patients with multiple injuries.

\section{Pre-Operative Planning}

1. Determination of Nail Diameter: It was measured at the level of Isthmus of femur in lateral X-ray.

2. Determination of Neck Shaft Angle: It was measured using goniometer on the normal side.

3. Length of Proximal Femoral Nail: A standard PFN length of $25 \mathrm{~mm}$ was used in our study.

Proximal Femoral Nail Operative Technique9:

All cases were operated under Spinal Anaesthesia with the patient lying in supine position in fracture table. Fracture reduction was done by applying traction, abduction and internal rotation sequentially and the reduction was checked with $\mathrm{C}$ arm.9,10 The reduced fracture is provisionally fixed by passing $\mathrm{K}$ wire in the anterior cortex parallel to neck. This prevents opening out of fracture during adduction of limb.

\section{Post-Operative Protocol}

Intravenous antibiotics were given for five days followed by oral antibiotics till suture removal. Alternate sutures were removed on $12^{\text {th }}$ day and complete suture removal by $14^{\text {th }}$ day. Blood transfusion if required was given. Patient was made to sit in the bed after 24 hours. Quadriceps exercises and knee mobilisation exercises were started immediately. Patients were asked to weight-bear using walker support depending on the pain tolerability of patient. Partial weight bearing allowed from fourth week and full weight bearing after clinical and radiological signs of union were noted. Patient was discharged from the hospital once partial weight bearing is achieved with walker support.

\section{Follow-up}

After discharge patient was asked to come for follow-up at 2 weeks, 1 month, 2 months and every month till fracture union occurs. Modified hip score ${ }^{11,12}$ was used for evaluation.

\section{Dynamic Hip Screw Operative Technique}

All cases were operated under spinal anaesthesia. Patient lies in supine position in the fracture table with the unaffected hip being placed in abduction and flexed position. Fracture reduction is done by applying longitudinal traction followed by abduction to correct varus and external rotation and then internal rotation of distal segment.

\section{Post-Operative Care}

1. Operated limb was elevated for a day.

2. Intravenous broad spectrum antibiotics were given for 5 days and then shifted to oral antibiotics.

3. Static quadriceps exercises were begun on $2^{\text {nd }}$ postoperative day.

4. Active quadriceps exercises and hip flexion exercises were started by 5 th post-operative day.

5. Patient was encouraged non-weight bearing ambulation with axillary crutches.

6. Alternate sutures were removed on 12th post-operative day and complete suture removal was done on 14th post-operative day.

7. Partial weight bearing was started at about 6 weeks post-operatively after noticing clinical and radiological union progressing at satisfactory levels.

8. Full weight-bearing was allowed only after the confirmation of radiological union and confirmation of clinical union by assessing pain, fracture gap and other parameters clinically.

\section{RESULTS}

\begin{tabular}{|c|c|c|c|c|}
\hline $\begin{array}{c}\text { Age } \\
\text { Group }\end{array}$ & $\begin{array}{c}\text { No. of Patients } \\
\text { in DHS Group }\end{array}$ & $\begin{array}{c}\text { No. of Patients in } \\
\text { PFN Group }\end{array}$ & Total & \% \\
\hline 55 to 60 & 8 & 10 & 18 & 45 \\
\hline 61 to 65 & 6 & 8 & 14 & 35 \\
\hline 66 to 70 & 4 & 0 & 4 & 10 \\
\hline 71 to 75 & 2 & 2 & 4 & 10 \\
\hline Total & $\mathbf{2 0}$ & $\mathbf{2 0}$ & $\mathbf{4 0}$ & \\
\hline \multicolumn{5}{|c}{ Table 1. Age wise Distribution of Patients } \\
\hline
\end{tabular}

1. In our study, majority of cases were in the age group of 55 to 65 years- 32 cases [80\%].

2. Mean age of patient in DHS group $=63.2$ years.

3. Mean age of patient in PFN group $=61.1$ years .

\begin{tabular}{|c|c|c|c|}
\hline Sex & DHS & PFN & \% \\
\hline Male & 12 & 16 & 70 \\
\hline Female & 8 & 4 & 30 \\
\hline Total & 20 & 20 & \\
\hline \multicolumn{2}{|l}{ Table 2. Sex wise Distribution of Cases } \\
\hline
\end{tabular}

Males predominate in our study [70\%].

\begin{tabular}{|c|c|c|c|c|}
\hline Side & DHS & PFN & Total & \% \\
\hline Right & 6 & 10 & 16 & 40 \\
\hline Left & 14 & 10 & 24 & 60 \\
\hline Total & $\mathbf{2 0}$ & $\mathbf{2 0}$ & $\mathbf{4 0}$ & \\
\hline \multicolumn{6}{|c|}{ Table 3. Side Distribution } \\
\hline
\end{tabular}


Majority of cases were left sided injuries

1. The mean duration of operation time is more in DHS group than the patients in PFN group and within the DHS group the duration is more in unstable fractures.

2. The mean blood loss is more in patients with unstable fractures who underwent DHS.

3. Mean length of incision is more in DHS group when compared to the PFN group.

\begin{tabular}{|c|c|c|}
\hline Factors & DHS & $\begin{array}{c}\text { Proximal } \\
\text { Femoral Nail }\end{array}$ \\
\hline $\begin{array}{c}\text { Mean Time of Operation } \\
\text { after Fracture in Days }\end{array}$ & 7.2 & 5.8 \\
\hline $\begin{array}{c}\text { Mean Duration of Operation in } \\
\text { Minutes }\end{array}$ & 69.9 & 52.1 \\
Stable Fracture & 60.8 & 44.3 \\
Unstable Fracture & 82.5 & 55.4 \\
\hline Mean Blood Loss in mL & 163 & 97.5 \\
Stable Fracture & 152.3 & 101.6 \\
Unstable Fracture & 180 & 95.7 \\
\hline Mean Length of Incision in cm & 9.1 & 5.6 \\
Stable & 9 & 5.57 \\
Unstable & 9.25 & 5.61 \\
\hline Table 4. Operative Details of Patients \\
treated for Pertrochanteric Fracture of Femur \\
\hline \multicolumn{2}{|c}{}
\end{tabular}

\begin{tabular}{|c|c|c|}
\hline Details & DHS & $\begin{array}{c}\text { Proximal } \\
\text { Femoral Nail }\end{array}$ \\
\hline $\begin{array}{c}\text { Mean Length of Lag } \\
\text { Screw in mm }\end{array}$ & 84.5 & 86 \\
\hline $\begin{array}{c}\text { Mean Nail Diameter } \\
\text { in mm }\end{array}$ & - & 9.8 \\
\hline \multicolumn{2}{|c|}{$\begin{array}{c}\text { Table 5. Implant Details of Patients treated } \\
\text { for Pertrochanteric Fracture of Femur }\end{array}$} \\
\hline
\end{tabular}

\begin{tabular}{|l|c|c|}
\hline Complications & DHS & PFN \\
\hline Failure of Reduction & 1 & 1 \\
Stable Fractures & 1 & \\
Unstable Fractures & & \\
\hline $\begin{array}{l}\text { Fracture of Lateral Cortex } \\
\text { Stable Fractures } \\
\text { Unstable Fractures }\end{array}$ & 0 & 0 \\
\hline $\begin{array}{l}\text { Jamming of Nail } \\
\text { Stable Fractures } \\
\text { Unstable Fractures }\end{array}$ & - & 0 \\
\hline $\begin{array}{l}\text { Difficulty in Introducing Two Screws in Neck } \\
\text { Stable }\end{array}$ & - & 1 \\
Unstable & & 1 \\
\hline $\begin{array}{l}\text { Failure of Distal Locking } \\
\text { Stable Fractures } \\
\text { Unstable Fractures }\end{array}$ & - & 1 \\
\hline $\begin{array}{l}\text { Drill Bit Breakage } \\
\text { Stable Fractures } \\
\text { Unstable Fractures }\end{array}$ & & \\
\hline \multicolumn{1}{|c|}{ Table 6. Intra-operative Complications of } \\
Patients treated for Pertrochanteric Fracture \\
\hline
\end{tabular}

\begin{tabular}{|l|c|c|}
\hline & DHS & PFN \\
\hline Fracture Reduction & & \\
Stable Fractures & 10 & 6 \\
Good & 2 & - \\
Fair & & \\
Unstable Fractures & 6 & 12 \\
Good & 2 & 2 \\
Fair & & \\
\hline Position of Lag Screw & 10 & 6 \\
Stable Fractures & 2 & \\
Good & & \\
Fair & 6 & 10 \\
Unstable Fractures & 2 & 4 \\
Good & 16 & 17.2 \\
Fair & \\
\hline Mean Tip apex distance ${ }^{13}$ in mm & Table 7. Radiological Outcome of Patients \\
\hline \multicolumn{2}{|c|}{ treated for Pertrochanteric Fracture of Femur } \\
\hline \multicolumn{2}{|c|}{} \\
\hline
\end{tabular}

Fracture reduction was good in stable fractures in DHS group and in both stable and unstable fractures in PFN group.

\begin{tabular}{|c|c|c|}
\hline & DHS & PFN \\
\hline Mean Duration of Hospital Stay in Days & 6.8 & 6.2 \\
\hline Time of Weight Bearing in Weak [Mean] & 9.5 & 3.6 \\
Stable & 7.3 & 3.6 \\
Unstable & 12.5 & 3.7 \\
\hline Pain in Hip & & \\
Stable & 2 & 2 \\
Unstable & 2 & 2 \\
\hline Pain in Thigh & 0 & 2 \\
Stable & 0 & 1 \\
Unstable & 0 & 1 \\
\hline Table 8. Post-operative Outcome of Patients \\
treated for Pertrochanteric Fracture of Femur \\
\hline
\end{tabular}

1. Mean duration of hospital stay is more in DHS group.

2. Time of initiating weight bearing is late in unstable type of fractures in DHS group.

3. Time of weight bearing is earlier in PFN group than DHS and is nearly equal for both stable and unstable type.

4. Pain in hip occurred in 2 cases in both DHS and PFN group.

5. Pain in thigh occurred in 2 cases of PFN group, but there is no case of pain in thigh in DHS group.

\begin{tabular}{|c|c|c|}
\hline & DHS & Proximal Femoral Nail \\
\hline Infection & 1 & 0 \\
\hline Lag Screw Cutting Out & 1 & 1 \\
\hline Fracture Femoral Shaft & 0 & 0 \\
\hline Shortening $>2 \mathrm{~cm}$ & 1 & 0 \\
\hline Varus Displacement $>10 *$ & 1 & 0 \\
\hline Table 9. Post-operative Complications of Patients \\
treated for Pertrochanteric Fracture of Femur \\
\hline
\end{tabular}

1. One case of infection was noted in DHS group.

2. One case of lag screw cut-out in DHS group ${ }^{14}$ and one case of 'Z' effect15 in PFN group observed.

3. In unstable fracture type of patients who underwent DHS, shortening of more than $2 \mathrm{~cm}$ was noticed in one case and varus displacement in one case. Both patients were advised implant exit and heel rise footwear for ambulation. 
4. There was no infection, no distal femoral shaft fracture, nor any shortening and varus displacement in PFN Group.

5. Post-operative complications are less in PFN group comparing to DHS group.

\begin{tabular}{|l|c|c|}
\hline & DHS & PFN \\
\hline Fracture Healing & & \\
Stable Fractures & 20 & 20 \\
Healed & 0 & 0 \\
Healed with $<10^{*}$ Varus Displacement & & \\
Unstable Fractures & 20 & 20 \\
Healed & 1 & 0 \\
Healed with <10* Varus Displacement & 19.9 & 15.2 \\
Mean Duration of Fracture Union in wks. & 18.6 & 14.6 \\
Stable Fractures & 22.5 & 15 \\
Unstable Fractures & \\
\hline \multicolumn{2}{|c|}{ Table 10. Radiological Outcome of Patients } \\
treated for Pertrochanteric Fracture of Femur \\
\hline \multicolumn{2}{|c}{}
\end{tabular}

1. Union occurred in all fractures in our study but there was one case of shortening and one varus malunion in unstable type in DHS group

2. Mean duration for the fracture to unite was quicker in PFN group [15.2 weeks] when compared to DHS group [19.9 weeks].

3. The duration of fracture union is more in unstable type comparing to stable type in DHS group but it is nearly same in both types in PFN group.

\begin{tabular}{|c|c|c|}
\hline & $\begin{array}{c}\text { Dynamic } \\
\text { Hip Screw }\end{array}$ & $\begin{array}{c}\text { Proximal } \\
\text { Femoral Nail }\end{array}$ \\
\hline Mean Harris Hip & 69.34 & 81.23 \\
Score in 6 Weeks & & \\
Mean Harris Hip & & \\
Score in 20 Weeks & 80.2 & 83.57 \\
\hline \multicolumn{2}{|c|}{ Table 11. Clinical Outcome of Patients } \\
treated for Pertrochanteric Fracture of Femur \\
\hline
\end{tabular}

1. Mean Harris hip score is more in PFN group at 6 weeks after surgery. But it becomes nearly equal in both groups at 20 weeks period.

2. PFN group had early rehabilitation and early weightbearing was started.

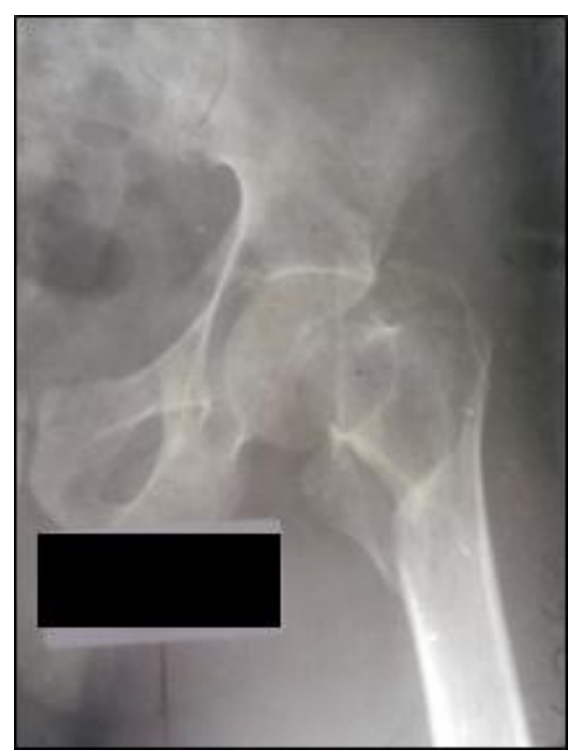

Figure 1. Preoperative

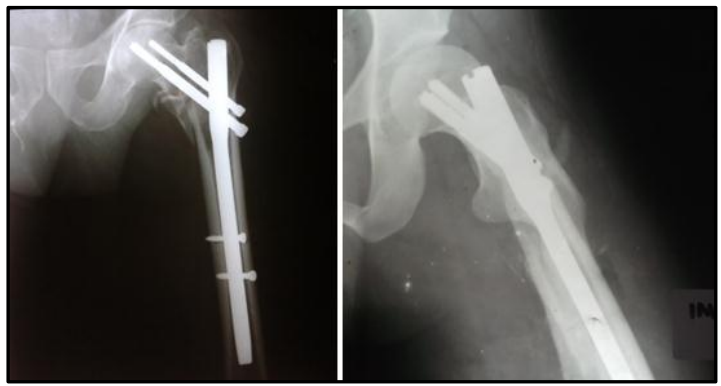

Figure 2. Immediate Post-operative AP \& Lat

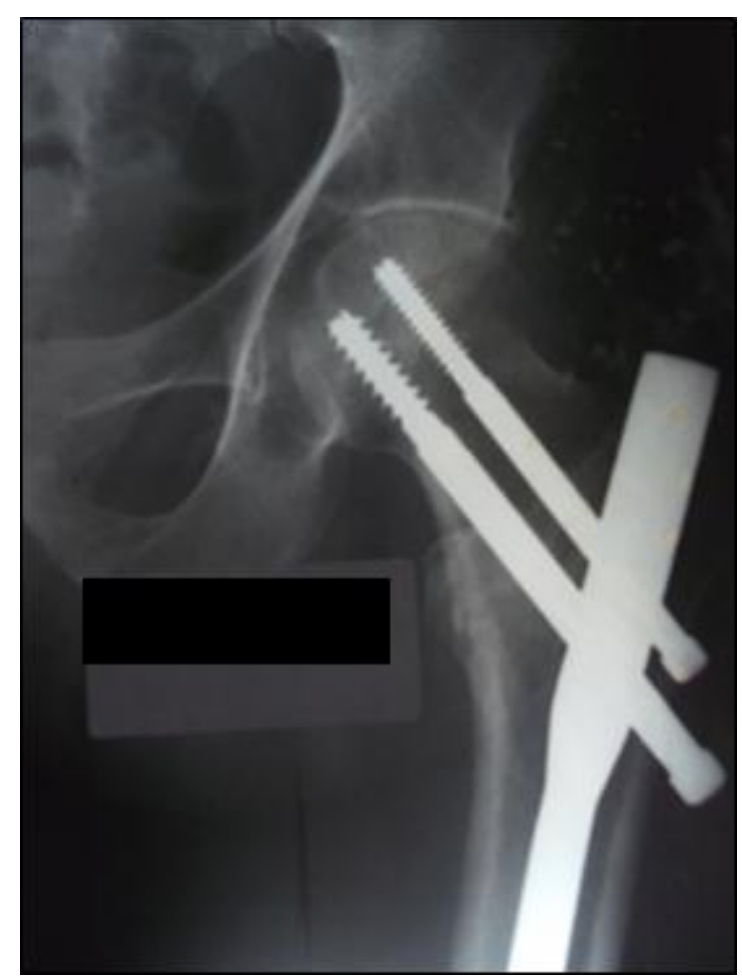

Figure 3. 6 Weeks Post-op

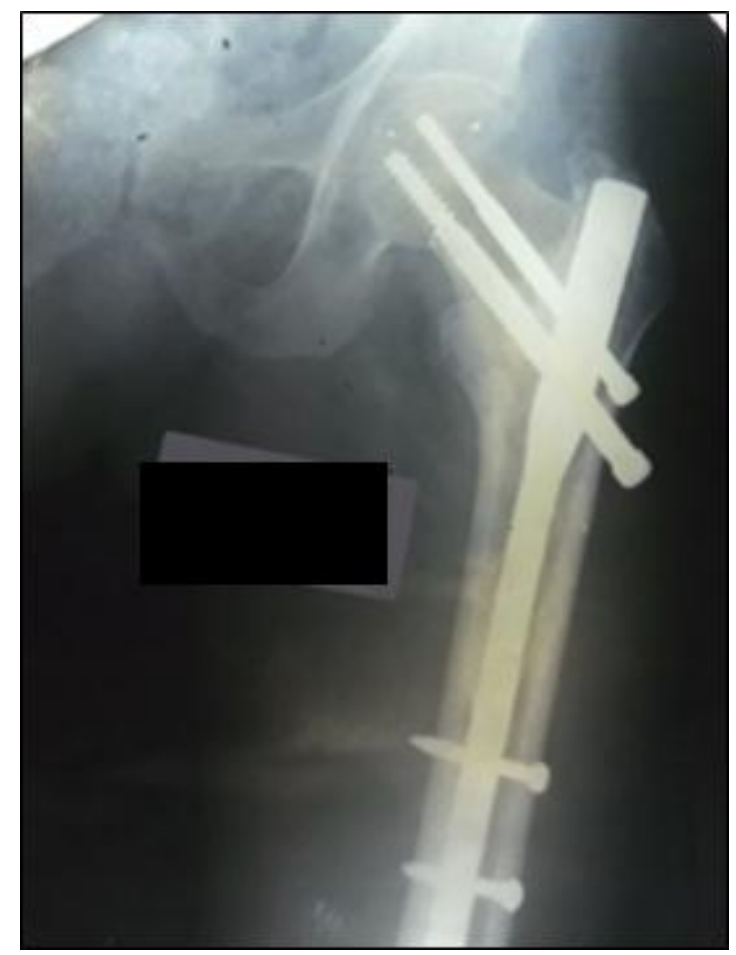

Figure 4. 4 Months Post-op 


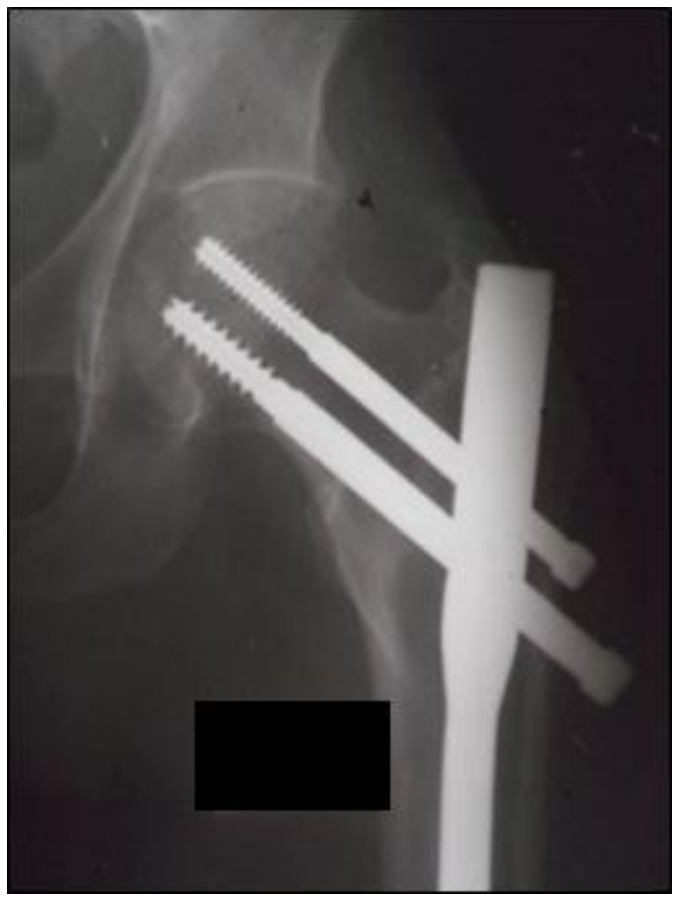

Figure 5. 1-year Post-op

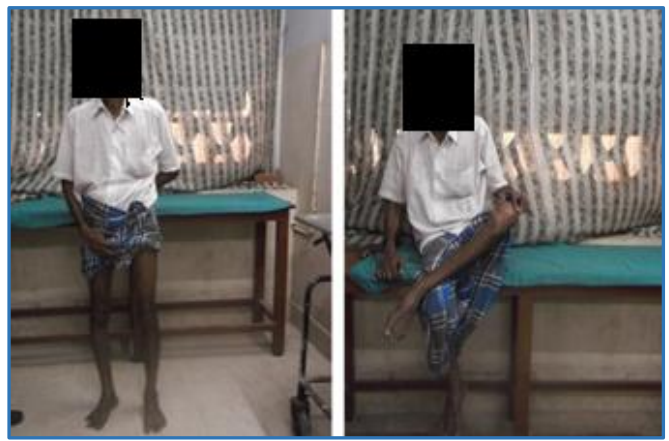

Figure 6. Clinical Photos 1-year Follow-up

DHS Case Illustration

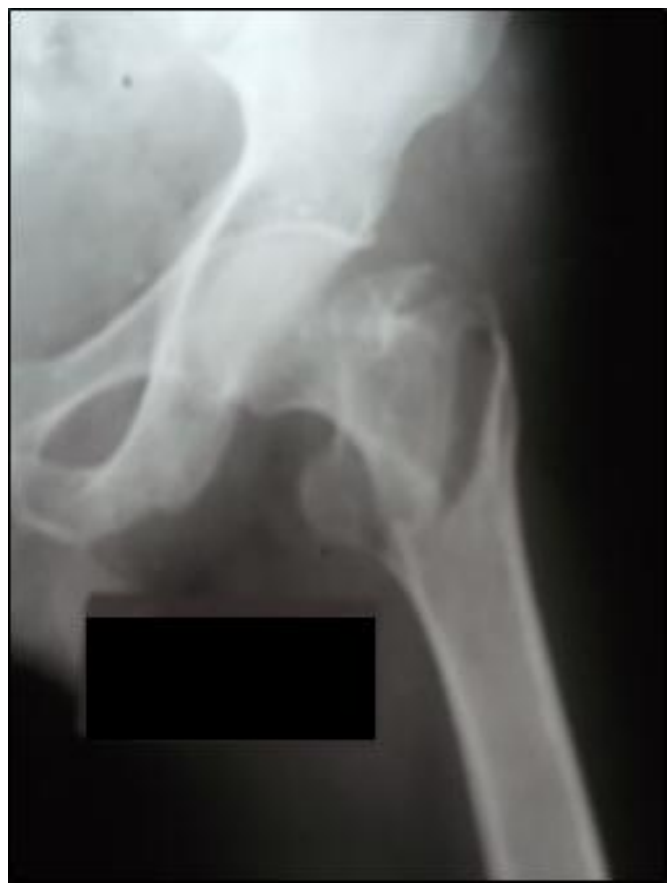

Figure 7. Preoperative

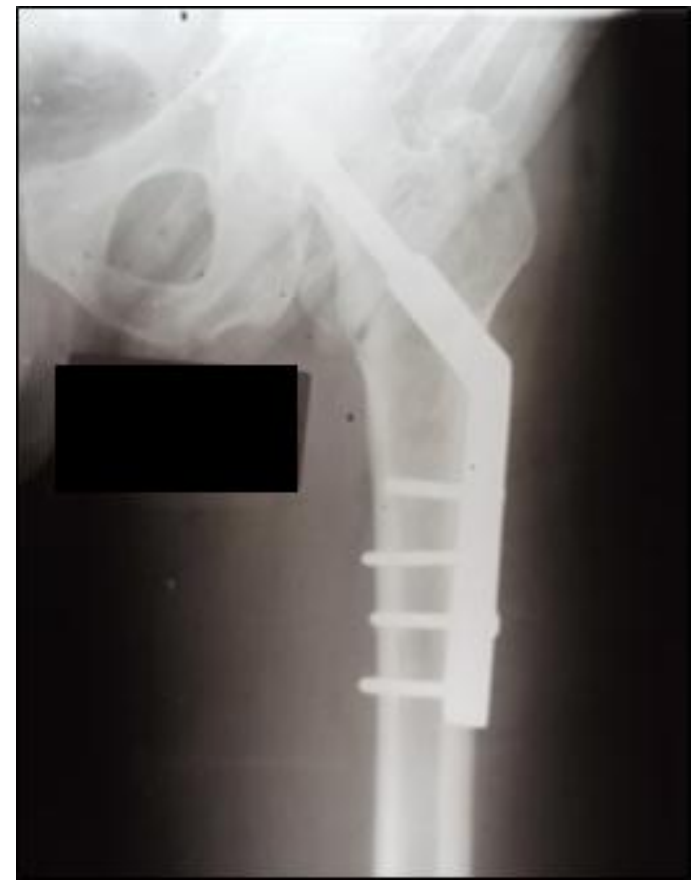

Figure 8. Immediate Post-op

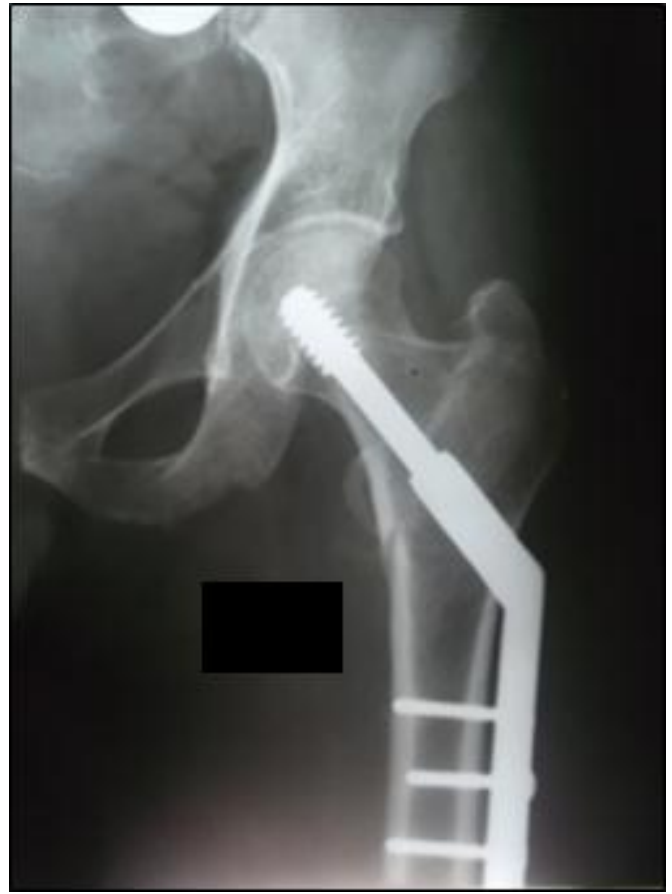

Figure 9. 2 Weeks Post-op

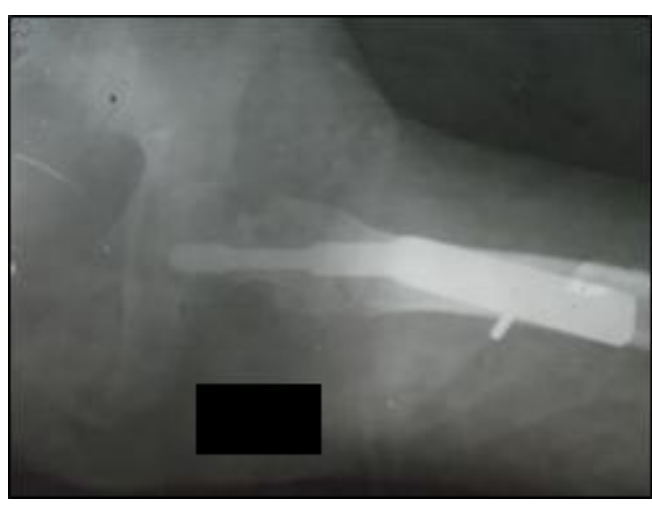

Figure 10. 2 Weeks Post-operative 


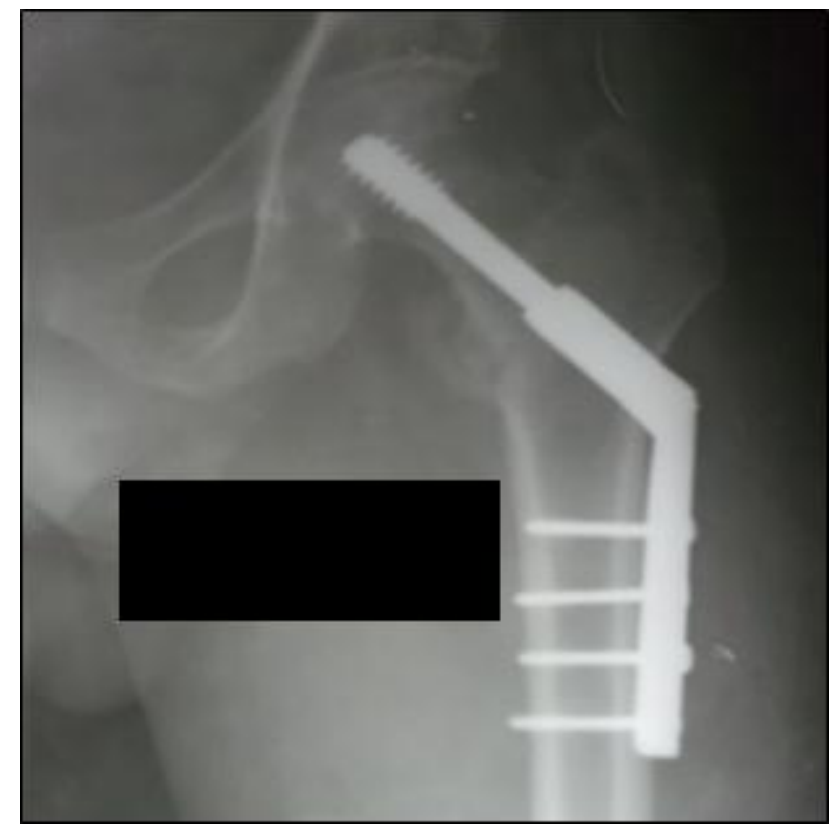

Figure 11. 1-1/2-month Post-operative

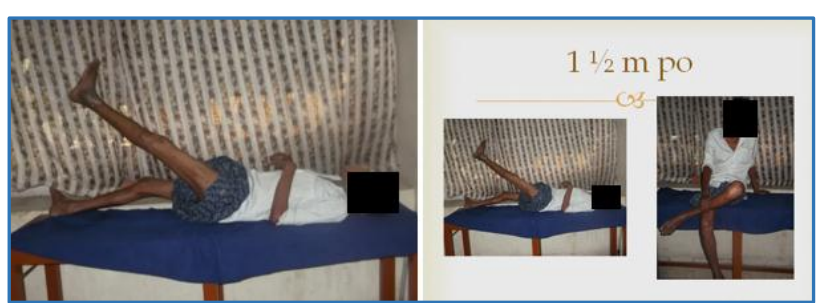

Figure 12. 1-1/2-month Post-op Clinical Photo of Range of Movements

\section{DISCUSSION}

\section{Associated Injures}

In our study series, we have found 2 patients with associated injuries amongst 20 patients operated by PFN, out of which 1 patient was having fracture of distal end radius and one patient had ipsilateral fracture of calcaneum. One patient had fracture of distal end radius on contra-lateral side. All were treated in same operative setting by closed manipulation reduction and followed by cast application (As patients were given general anaesthesia). To minimise the risk of complications conservative method was chosen for both the distal radius fractures, while one patient with ipsilateral fracture calcaneum was also treated conservatively.

\section{COMPLICATIONS}

\section{Systemic Complications}

In patients treated with PFN as well as DHS, one patient in each group was found to have chest infection while in one other patient we found complication of urinary tract infection. The patients with chest infection were known cases of COPD, as they were chronic beedi smokers. Appropriate treatment was given before surgery. Prolonged catheterisation was noted as a cause for urinary traction infection which was treated with appropriate antibiotics.

\section{Operative Wound Complications}

In the group of patients who underwent DHS, one patient developed superficial wound infection. The superficial infection may be attributed to the glycaemic status of patient as he was a known diabetic without proper glycaemic control. The wound healing in this patient occurred after being treated with prolonged intravenous antibiotics. There was also more soft tissue exposure in DHS group.

\section{Implant Related Intra-operative Complications}

In two cases of PFN, during surgery we encountered ill-fitting jig. Due to this the corresponding holes in jig did not match with holes in proximal part of nail and proximal screw insertion was a problem. Besides this we had one case in which there was difficulty in fracture reduction and in one case there was a failure in distal locking.

In the DHS group, we had difficulty in reduction in one case which was due to delay in surgery as it was a known case of diabetic and hence was operated late.

\section{Rotational Malalignment}

External rotational deformity of $15^{*}$ was noted in one case of PFN group. Varus deformity was noted in one case in DHS group, which was due to excessive back-out and screw cutout. Shortening of 0.8 to $1 \mathrm{~cm}$ was noted in 2 unstable cases in DHS group but they had no walking abnormality.

\section{Radiological Complications}

In PFN group we encountered one case of ' $\mathrm{Z}$ ' effect and there was no case of reverse ' $\mathrm{Z}$ ' effect.

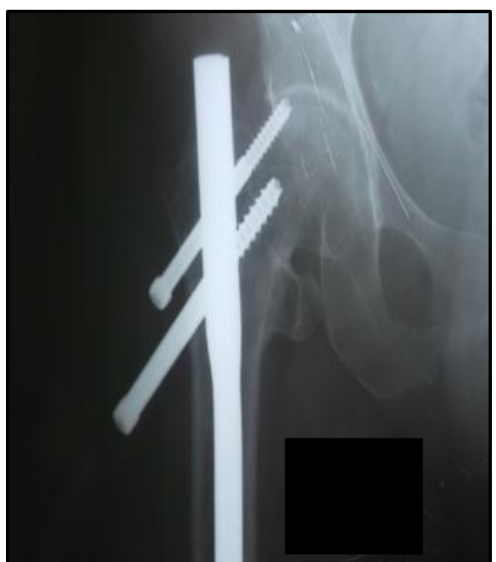

Figure 13. X-ray showing Z Effect in PFN

In DHS group, we had one case of screw cut-out.

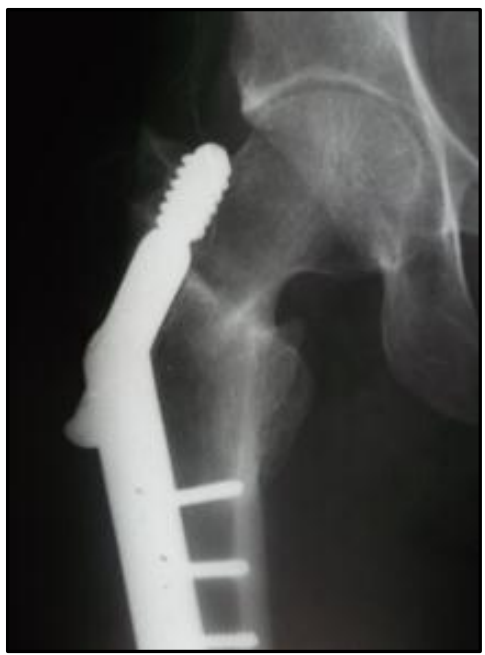

Figure 14. X-ray showing Screw Cut-out in DHS 


\section{Other Complications}

Radiation exposure was more in PFN group than in DHS group.

Blood loss measured by mop count [each fully soaked mop counting $50 \mathrm{~mL}$ ] is more in DHS group which is because of wide exposure.

\section{Range of Movement}

Range of movement was evaluated clinically during followup. Modified Harris Hip Score was used to determine the outcome. The score was in favour of PFN group after six weeks of operation. But at the end of twenty weeks it became nearly equal.

Our study was conducted at Government Royapettah Hospital from 2012 to 2014. 40 patients were included in our study with 20 in DHS group and 20 in PFN group. Each case was followed up for at least 6 months and in each visit clinical radiological and functional outcome was noted. These details were analysed, evaluated and compared.

\section{Type of Fractures}

In the study, we have 18 (45\%) intertrochanteric fractures with Evans stable, 22 (55\%) cases were of Evans unstable fractures. In our study of 40 patients, we had 18 (45\%) intertrochanteric fractures with Evans stable type of fracture pattern and 22 (55\%) cases were of Evans unstable fracture pattern. Out of the 18 Evans stable intertrochanteric fractures, 12 patients underwent DHS and 6 patients underwent PFN. In the Evans unstable Intertrochanteric fracture group of 22 patients, 8 patients underwent DHS and 14 patients underwent PFN. Majority of patients in present study series were operated within 10 days following admission in hospital (34/20). In 6 patients, the time to surgery was delayed as the patients presented late to hospital for treatment.

\section{Period of Hospitalisation}

Average time of admission in the hospital was 21 days i.e. 3 Weeks.

\section{Mobilisation}

We found the mobilisation of patients operated by both PFN and DHS in our study was almost same but the weightbearing of patients in the PFN group was earlier.

\section{Average Time of Fracture Union}

Average time of union in all our 40 patients was about 16 weeks (Range: 12 to 20 weeks).

\section{Intra Operative Radiation Exposure and Mean Blood Loss}

There is comparatively less blood loss in patients managed by Proximal Femoral Nail as compared to patients of Dynamic Hip Screw group. The mean blood loss in PFN group was 120 millilitres of blood while the mean blood loss in DHS group was 180 millilitres.

The average time of screening by image intensifier was lesser in cases operated by DHS as compared to those operated by PFN. The less exposure in DHS is because of wide exposure. In PFN group, radiation is more during proximal screw insertion.
Range of movement by Harris Hip score was in favour of PFN group at 6 weeks postoperatively but it becomes equal at 20 weeks.

\section{CONCLUSION}

1. The advantages of PFN were - smaller incision, less blood loss, less morbidity.

2. Proximal Femoral Nail possesses shorter lever arm and lower bending movement which provided added mechanical advantage to the construct.

3. PFN found to be the implant of choice in osteoporotic bones.

4. Malrotation and deformity in treating Pertrochanteric fracture found to be less in our study.

5. Mean blood loss was less in PFN group.

6. Varus collapse and shortening in unstable was more in DHS group than PFN group.

7. There was no femoral shaft fracture in our study though it was reported as one of the complications in literature.

8. The learning curve of DHS was smaller comparing to PFN.

9. Radiation exposure was less in DHS than in PFN.

10. Implant related complications during surgery were less in DHS than in PFN.

11. Rate of fracture union was similar in both groups with early mobilisation in PFN group.

12. DHS found to be the implant of choice as far as stable fracture is concerned. But for unstable fracture the pendulum swings in favour of PFN.

Thus, we can safely conclude that choice of implants depend on the experience of the surgeon and the type of fracture pattern. In our study, we also conclude that fixation of pertrochanteric fractures aid early rehabilitation and early weightbearing.

\section{REFERENCES}

[1] Anglen JO. Intertrochanteric osteotomy for failed internal fixation of femoral neck fracture. Clin Orthop Relat Res 1997;341:175-82.

[2] Ansari Moein CM, Verhofstad MH, Bleys RL, et al. Soft tissue injury related to choice of entry point in antegrade femoral nailing: pyriform fossa or greater trochanter tip. Injury 2005;36(11):1337-42.

[3] Albareda J, Laderiga A, Palanca D, et al. Complications and technical problems with the gamma nail. Int Orthopl 1996;20(1):47-50.

[4] Al-yassari G, Langstaff RJ, Jones JW, et al. The AO/ASIF proximal femoral nail (PFN) for the treatment of unstable trochanteric femoral fracture. Injury 2002;33(5):395-9.

[5] Anne AK, Ekeland A, Odegaard B, et al. Gamma nail versus compression screw for trochanteric femoral fracture: 15 reoperations in a prospective, randomized study of 378 patients. Acta Orthop Scand 1994;65(2):127-30.

[6] Babhulkar SS. Management of trochanteric fractures. IJO 2006;40(4):210-8.

[7] Davis TR, Sher JL, Horsman A, et al. Intertrochanteric femoral fractures. Mechanical failure after internal fixation. J Bone Joint Surg Br 1990;72(1):26-31. 


\section{Jemds.com}

[8] Evans EM. The treatment of trochanteric fractures of the femur. J Bone Jt Surg 1949;31-B(2):190-203.

[9] Domingo LJ, Cecilia D, Herrera A, et al. Trochanteric fractures treated with a proximal femoral nail. Int Orthop 2001;25(5):298-301.

[10] Dousa P, Bartonicek J, Jehlicka D, et al. Osteosynthesis of trochanteric fracture using proximal femoral nails. Acta Chir Orthop Traumatol Cech 2002;69(1):22-30.

[11] Harris WH. Traumatic arthritis of the hip after dislocation and acetabular fractures: treatment by mold arthroplasty. An end-result study using a new method of result evaluation. J Bone Joint Surg Am 1969;51(4):737-55.

\section{Original Research Article}

[12] Ragab AA. Validity of self-assessment outcome questionnaires: patient-physician discrepancy in outcome interpretation. Biomed Sci Instrum 2003;39:579-84.

[13] Baumgaertner MR, Curtin SL, Lindskog DM, et al. The value of the tip-apex distance in predicting failure of fixation of pertrochanteric fractures of the hip. J Bone Joint Surg Am 1995;77(7):1058-64.

[14] Hsueh KK, Fang CK, Chen CM, et al. Risk factors in cutout of sliding hip screw in intertrochanteric fractures: an evaluation of 937 patients. Int Orthop 2010;34(8):1273-6.

[15] Strauss EJ, Kummer FJ, Koval KJ, et al. The "Z-effect" phenomenon defined: a laboratory study. J Orthop Res 2007;25(12):1568-73. 